\title{
MJN THE EFFECTS OF TAI CHI EXERCISE ON PHYSIOLOGICAL AND PSYCHOSOCIAL WELL-BEING DURING ADJUVANT CHEMOTHERAPY AMONG BREAST CANCER PATIENTS
}

\author{
Salwa Attia. Mohamed ${ }^{1 *}$, Asmaa Abouda Abdelhamed Soultan ${ }^{2}$ \\ ${ }^{1}$ Medical Surgical Nursing, Faculty of Nursing, Fayoum University, Egypt \\ ${ }^{2}$ Medical Surgical Nursing, Faculty of Nursing, Damietta University, Egypt \\ *Corresponding Author's Email: salwaflower@yahoo.com
}

\begin{abstract}
Background: Tai Chi (TC), as a mind-body exercise, may have a positive impact on physical function and psychological well-being in breast cancer patients. Objective: The aimed of the study is to evaluate the effects of Tai Chi exercise on physiological and psychosocial well-being during adjuvant chemotherapy among breast cancer patients. Methods: A purposive sample of 70 patients undergoing chemotherapy diagnosed of breast cancer. Quasi-experimental design was utilized to conduct this study at the outpatient clinic regarding breast cancer with chemotherapy health insurance (Alfardose Clinic) Mansoura, Egypt. A structured interviewing questionnaire included patient demographic and medical data, psychological changes associated with chemotherapy and Hospital Anxiety and Depression Scale to assess Well-Being were used as a tool for data collection. Results: There were highly statistically improvement in studied samples' regarding drowsy, tiredness, depression and worry symptoms post and follow up of implementation Tai Chi Exercise. Conclusion: The participants of the study felt that Tai Chi had been greatly beneficial to them, both in terms of improving physiological and physical well-being. Recommendations: Tai Chi Exercise should be applied to all breast cancer patients undergoing chemotherapy because of its effectiveness in improving the physiological and psychological status after implementing the program.
\end{abstract}

Keywords: Tai Chi Exercise; Well-Being; Adjuvant Chemotherapy and Breast Cancer

\section{INTRODUCTION}

Breast cancer $(\mathrm{BC})$ is the most frequent cancer death among females, estimated 2.1 million new cases of breast cancer were expected to be diagnosed each year. More than one-half of breast cancer cases worldwide occur in the developing world, while generally lower in the Middle East and North Africa than in North America and Europe, is rising quickly. Although Egypt has a similar incidence to its neighboring Arab countries, it has a high breast cancer mortality rate of 21.3 per 100,000 cases (Gany et al., 2020).

Despite the increased survival rates experienced by women diagnosed with breast cancer, treatments for the disease result in negative side effects, such as decreases in functional capacity, fatigue, nausea, vomiting, alopecia, depression, poor body image and decreases in self-esteem that persist long after treatments have ended (Park et al., 2018).
Cancer and its treatment can have a profound impact on functioning in usual activities and well-being for many months or even years. In addition, nausea and vomiting are still considered a significant stress to patients and also cancer-related fatigue, cognitive diminishing, reduced sleep quality, depression anxiety, fear of recurrence, and lead to a diminished quality of life (QoL) (Berhili et al., 2017; Fabi et al., 2020).

Tai Chi (TC) has gained more popularity worldwide, mind-body exercises that incorporates physical activity, mindful meditation, and controlled breathing. Tai Chi provides both physical and psychological benefits for breast cancer patients after treatments. These benefits include improvements in fatigue, sleeping, pain, functional capacity, depression, and self-esteem (Liu et al., 2018). So, these benefits would be enhanced were Tai Chi to be applied earlier during the process of cancer therapy (Ding et al., 2020).

Currently the study shows further development of 
patient education and support throughout the process of $\mathrm{BC}$ management is needed to improve the overall quality of patient care through an integrative treatment program, consisting of Tai Chi exercise with walking may offer a reasonable and novel therapeutic approach (Hissa et al., 2020).

The chemotherapy nurse has an important role, the not only identification and management of these patients but also in patients' education about cancer and lifestyle modifications. Evidence suggests that nurses can improve care by communicating effectively with patients and helping them to understand their illness and concordance with medication and nutritional needs (Osborn et al., 2020).

\section{Significance of the Study}

Breast cancer is the greatest common cancer among women, estimated 2.1 million ladies yearly, and furthermore causes the utmost number of cancerrelated deaths among women. In 2018, it is that impacting 627,000 women dead from breast cancer that is around $15 \%$ of all cancer deaths among women. While breast cancer rates are higher among women in more developed areas, rates are increasing in closely every region globally (Gilchrist et al., 2019). There is growing awareness that cancer fighters represent a population with several needs related to physical conditioning, cardiovascular disease risk, and psychological stress. TC exercise as an intervention may deliver benefits to cancer survivors in these several areas of need established on meditation and aerobic exercise (Pan et al., 2018).

\section{Aim of the Study}

The aim of this study was to evaluate the effects of Tai Chi exercise on physiological and psychosocial well-being during adjuvant chemotherapy among breast cancer patients

\section{Methodology}

\section{Research Hypotheses}

H.1 Patients expected physiological well-being will improve post implementation of Tai Chi Exercise.

H.2 Cancer Patients undergoing chemotherapy will experience less psychosocial symptoms post practices Tai Chi exercise.

\section{Research design}

The quasi-experimental (pre/posttest) research design was utilized to conduct this study.

\section{Setting}

This study was carried out at the outpatient clinic regarding breast cancer with chemotherapy health insurance (Al fardose Clinic) Mansoura, Egypt.

\section{Sample}

A purposive sample of 70 patients undergoing chemotherapy diagnosed of breast cancer during period from October 2019 to January 2020.

\section{Tool for Data Collection:}

Comprised of three main parts to assess the followings:

Part 1: Demographic characteristic and medical data: to assess age, education, marital status, occupation, residence, caregiver, monthly income, and family size associated chronic diseases.

Part 2: Physiological assessment for patient state: aimed to assess the physiological distressed associated with chemotherapy pre and post implementing Tai Chi exercise.

Part 3 : Patients psychological well-being was assessed by Hospital Anxiety and Depression Scale (HADS). It was developed by Zigmond and Snaith, (1983) and modified by Bjelland, et al. (2002). This is a questionnaire used to determine the levels of anxiety and depression that a person is experiencing. Zigmond and Snaith, created this outcome measure specifically to avoid reliance on aspects of these conditions that are also common somatic symptoms of illness.

\section{Scoring}

Each item on the questionnaire is scored from 0-3 and this means that a person can score between 0 and 21 for either anxiety or depression. It classified as Normal (0-7), Borderline case (8-10) and Case (11-21).

\section{Content Validity and Reliability}

The study tools were tested for validity by five experts in the field of Medical Surgical Nursing. The face validity of the questionnaire was calculated based on experts' opinion after calculating content validity index (\%) of its items and it was $94 \%$. The study tools were subjected to assessment of internal consistency reliability using Spearman-Brown Prophecy Formula $(\mathrm{r} 1=2(3) / 1+\mathrm{r})$, where $\mathrm{rl}$ estimated reliability of the entire test and $\mathrm{r}$ estimated correlation coefficient computed on the split halves. It was 0.896 . 


\section{Ethical Considerations}

Verbal approval was obtained from each subject who agreed to participate before inclusion in the study. A clear and simple explanation from purpose of the study and they were reassured about the confidentiality of the information. Also, informed about their rights to refuse participation or withdraw at any time.

\section{Procedure}

- The researcher reviewed current local and international related literature, which helped to be more acquainted with the topic, and with the process of study tool construction. Then, tool was designed and tested for being valid through a pilot study.

- A pilot study was carried out on (10\%) of the study patients 7 female with breast cancer; they were not included in the study participants. It was done in order to test the clarity and applicability of the tool and estimate the time needed for the interview. Also, to detect any obstacles or problems that might arise in data collection. There was no modification needed.

- Prior to data collection the researcher introduced herself and explained the purpose of the study.

- The researchers obtained informed consent from each patient who agreed to participate in the Tai Chi Exercise program and before the questionnaire was administered.

- The researcher was using the study tool with collaborating of medical staff responsible about the cancer clinic in the chosen settings, as they were oriented about the concept of the Tai Chi Exercise program.

- Teaching sessions pre and post chemotherapy were conducted in patients' waiting area. The average time consumed to fill the tool was 20 minutes.

- Data collection was conducted a period of three months (from October 2019 to January 2020).

- A pretest was conducted as a first level of intervention by distributing the interviewing structured questionnaire.

- The patients met 3 times a week for 30 minutes in the waiting room for chemotherapy.

- The application of the Tai Chi exercise program for each patient individually through video, and role play methods. This session take about 30 minutes starting with theoretical part about the Tai Chi exercise meaning and benefits for the breast cancer patients then followed by practical application of the exercise then reapplication with the patients and booklet with instruction to practice exercise given for patients. During the last 30 minutes of each session, participants were instructed in regulatory breathing, imagery, and meditation in order to enhance their TC skills and provide an exercise cool-down.

\section{Doing Tai chi exercises:}

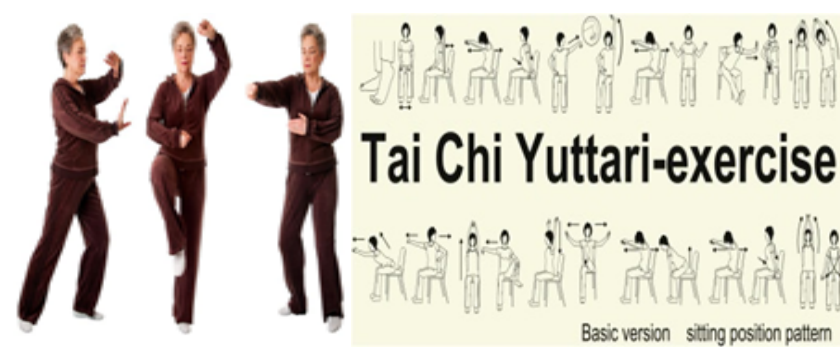

Standing position

Sitting position

\section{Figure 1: Tai Chi exercise standing and sitting}

Adapted from: https://encrypted-tbn0.gstatic.com/ images? $=$ =tbn:ANd9GcTUJCH0S4h18oBHPeVRXX2 PyZFxSDRM0-KJem1s_ilmd4WjpkbE\&s

The intervention group practiced Tai Chi exercise has standing or sitting, and has been advised to be performed by older female who might be fatigue, using a chair to prevent falls, show figure 1. (Nomura et al., 2011). A tai chi class might include these parts:

Warm-up: Shoulder circles, turning the head from side to side, help you to loosen your muscles and joints and focus on your breath and body.

Moving step with arms moving: Take a step to the left with your left foot while keeping your right foot in place so that the toes of the left foot touch the ground, then the second and third toes, etc.

Move the body to the left: You move your foot at an angle of 45 degrees and move the body weight towards the right foot and make an imaginary circle in the foot with the right hand raised to the top, then turn left and take an empty step towards the north with the left foot. Pictures help you make the final stand.

Ball catching position: The initial posture of this model is to stand with the ball facing you in the east. This form is one of the most important things about tai chi because it encompasses most of its basic principles. 
Feng: At the same time, take an empty step forward at a 45-degree angle so that the heel does not touch the ground, and then return by moving the weight forward.

Lowe: Then turn your foot slightly backward, transfer your weight, and then pull your hands in front of the center. These details are very important to use in martial arts so that you can defend yourself against your opponent.

- The session closure by asking the patients their feedback about the previous mentioned items; however, they were encouraged to practice the TC and behavioral coping strategies they learned during the sessions.

- The researchers re assess the patients' physical and psychological status using the pretest immediate posttest and one month follow up.

\section{Statistical analysis}

The collected data were organized, tabulated and statistically analyzed using SPSS software (Statistical Package for the Social Sciences, version 16, SPSS Inc. Chicago, IL, USA). For quantitative data, the range, mean and standard deviation were calculated. For qualitative data, which describe a categorical set of data by frequency, percentage or proportion of each category, comparison between pre and post was done using Chisquare test $\left(X^{2}\right)$. For comparison between means of two groups of parametric data of independent samples, student t-test was used. For comparison between means of two related groups (pre and post program intervention) of parametric data, paired $t$-test was used. For comparison between more than two means of parametric data, $F$ value of ANOVA test was calculated. Correlation between variables was evaluated using Pearson's correlation coefficient (r). Significance was adopted at $p<0.05$ for interpretation of results of tests of significance.

\section{RESULTS}

Figure 2 illustrates percentage distribution of age. It is clear that that $51.4 \%$ of study sample were in the age group of more than 55 years with mean age $53 \pm 9$ years.

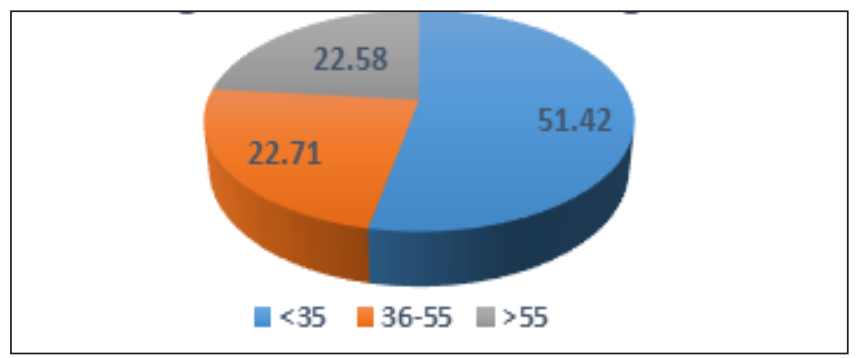

Figure 2: Distribution of Age
Table 1: Distribution of Demographic Characteristics of the Studied Sample $(N=70)$.

\begin{tabular}{|c|c|c|}
\hline \multirow{2}{*}{ Demographic data } & \multicolumn{2}{|c|}{ The studied sample $(\mathrm{N}=70)$} \\
\hline & No. & $\%$ \\
\hline Mean \pm SD & \multicolumn{2}{|c|}{$53.000 \pm 9.06837$} \\
\hline Female gender: & 70 & 100 \\
\hline \multicolumn{3}{|l|}{ Marital status: } \\
\hline - Single & 8 & 11.4 \\
\hline - $\quad$ Married & 32 & 45.7 \\
\hline - Widow & 30 & 42.9 \\
\hline \multicolumn{3}{|l|}{ Educational level: } \\
\hline - $\quad$ Illiterate & 8 & 11.4 \\
\hline - $\quad$ Read and write & 6 & 8.6 \\
\hline - $\quad$ Secondary education & 6 & 8.6 \\
\hline - University & 46 & 65.7 \\
\hline - Others & 4 & 5.7 \\
\hline \multicolumn{3}{|l|}{ Occupation: } \\
\hline - Teacher & 10 & 14.3 \\
\hline - Employee & 26 & 37.1 \\
\hline - Housewife & 6 & 8.6 \\
\hline - Others & 28 & 40 \\
\hline \multicolumn{3}{|l|}{ Work status after diagnosis: } \\
\hline - Not work & 6 & 8.6 \\
\hline $\begin{array}{l}\text { - Work usual determined } \\
\text { time }\end{array}$ & 8 & 11.4 \\
\hline - $\quad$ Part time & 24 & 34.3 \\
\hline - Leave work & 6 & 8.6 \\
\hline - Work in new job & 4 & 5.7 \\
\hline - $\quad$ Retirement & 22 & 31.4 \\
\hline \multicolumn{3}{|l|}{ Family responsibility: } \\
\hline - Have responsibility & 56 & 80 \\
\hline - Haven't responsibility & 14 & 20 \\
\hline \multicolumn{3}{|l|}{ Significance person: } \\
\hline - Nothing & 6 & 8.6 \\
\hline - $\quad$ Sister & 6 & 8.6 \\
\hline - Husband & 18 & 25.7 \\
\hline - Others & 40 & 57.1 \\
\hline \multicolumn{3}{|l|}{ Living with: } \\
\hline - Alone & 4 & 5.7 \\
\hline - Family & 60 & 85.7 \\
\hline - Others & 6 & 8.6 \\
\hline \multicolumn{3}{|l|}{ Income: } \\
\hline - Enough & 18 & 25.7 \\
\hline - Not enough & 52 & 74.3 \\
\hline
\end{tabular}


Table 1: Characteristic of the studied patients illustrated that $45.7 \%$ of sample were married $85.7 \%$ living with their family, $74.3 \%$ had not enough income. In relation to education level 65.7 percent of the sample had completed their University education. As regards to occupation $37.1 \%$ of studied sample were employee. As well as around one third of the sample had part time of work while $31.4 \%$ were retirement from their work. Table I shows also $80 \%$ of sample were had social responsibility.

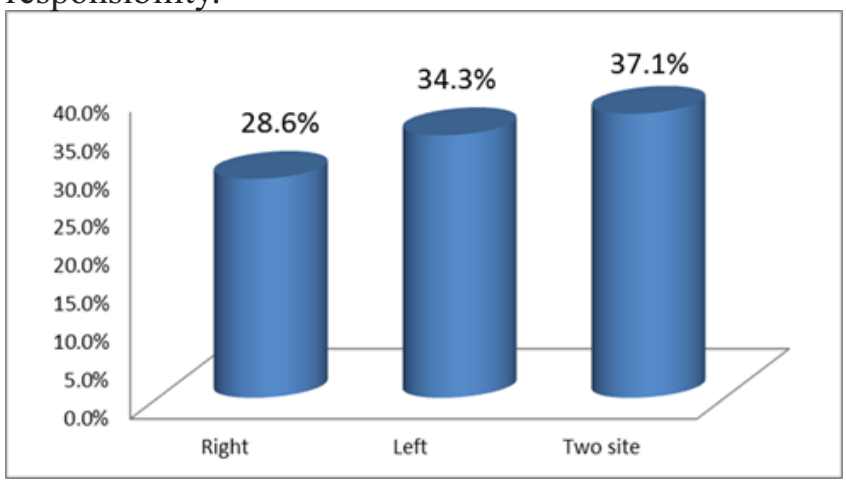

Figure 3: Distribution of The Sample According to Breast Cancer Site $(n=70)$.

Figure 3 Shows That The More Than One Third of The Sample (37.1\%) Was Two Sites, While The Minority Of Sample (28.6\%) Was Right.

Table 2 shows that $60 \%$ of study sample had started chemotherapy since 2018, near to half of them treated with Taxanes (taxol $60 \mathrm{mg}$, or $130 \mathrm{mg}$ ). While more than half had arthritis associated with disease. Related to weight $25.7 \%$ of the sample had overweight around 90 $\mathrm{kg}$ and more. With height $160: 175 \mathrm{~cm}$ archived by 62.9 $\%$.

Table 3 shows that there was highly statistically improvement in the studied samples' actual symptoms pre, immediate and follow up test post program regarding drowsy, tiredness, depression and worry, post implementation of Tai Chi Exercise program when comparing with pre, post of Tai Chi Exercise program, at $(p \leq 0.001)$.

Table 4 shows that there was highly statistically improvement in total scores and levels of studied sample's Symptoms pre, immediate and follow up post implementation of program.

Table 5 This table confirmed that there was high statistical significant differences between pre and post in Level of total anxiety and depression scale also were high significant differences between pre and follow up at $(p \leq 0.001)$.

Table 2: Distribution of Studied Samples' Medical History $(n=70)$.

\begin{tabular}{|c|c|c|}
\hline \multirow{2}{*}{ Medical history } & \multicolumn{2}{|c|}{ The studied sample $(\mathrm{N}=70)$} \\
\hline & No. & $\%$ \\
\hline \multicolumn{3}{|l|}{ Chronic diseases: } \\
\hline Arthritis & 40 & 57.1 \\
\hline Diabetes & 8 & 11.4 \\
\hline Chest disease & 6 & 8.6 \\
\hline Hypertension & 4 & 5.7 \\
\hline All of the above & 6 & 8.6 \\
\hline Others & 6 & 8.6 \\
\hline \multicolumn{3}{|l|}{ Weight } \\
\hline$<60$ & 12 & 17.1 \\
\hline $60-80$ & 28 & 40 \\
\hline$\geq 80$ & 30 & 45.8 \\
\hline \multicolumn{3}{|l|}{ Height } \\
\hline$\leq 160$ & 26 & 37.1 \\
\hline $160-175$ & 44 & 62.9 \\
\hline
\end{tabular}

Table 3: Total Scores and Levels of Studied Sample's Symptoms Pre, Immediate and Follow up Post Implementation of Program (No. $=70)$.

\begin{tabular}{|c|c|c|c|c|c|c|c|c|}
\hline \multirow{3}{*}{ Items } & \multicolumn{6}{|c|}{ The studied sample $(\mathrm{N}=70)$} & \multirow{3}{*}{$\chi^{2}$} & \multirow{3}{*}{$P$-Value } \\
\hline & \multicolumn{2}{|r|}{ Pre } & \multicolumn{2}{|c|}{ Immediate post } & \multicolumn{2}{|c|}{$\begin{array}{l}\text { Follow - up } \\
\text { One month }\end{array}$} & & \\
\hline & No. & $\%$ & No. & $\%$ & No. & $\%$ & & \\
\hline \multicolumn{9}{|c|}{ Level of Total Symptoms } \\
\hline Not Present & 38 & 54.3 & 58 & 82.9 & 42 & 60 & & \multirow{3}{*}{0.000} \\
\hline Present & 32 & 45.7 & 12 & 17.4 & 28 & 40 & 32.797 & \\
\hline $\begin{array}{l}\text { Range } \\
\text { Mean } \pm \text { SD }\end{array}$ & 14.514 & $\begin{array}{c}(0-30) \\
\pm 6.0714\end{array}$ & 4.828 & $\begin{array}{l}0) \\
4.662\end{array}$ & 12.68 & $\begin{array}{l}(0-24) \\
6 \pm 10.0163\end{array}$ & & \\
\hline \multirow{2}{*}{$T$-test } & \multicolumn{4}{|c|}{ Pre Vs. Immediate post } & \multicolumn{4}{|c|}{ Pre Vs. Follow-up } \\
\hline & \multicolumn{4}{|c|}{0.903} & \multicolumn{4}{|c|}{6.228} \\
\hline$P$-Value & \multicolumn{4}{|c|}{0.373} & \multicolumn{4}{|c|}{0.000} \\
\hline
\end{tabular}


Table 4: Distribution of Studied Patients Actual Symptoms Pre, Immediate and Follow up Test Post Program (No. =70)

\begin{tabular}{|c|c|c|c|c|c|c|c|c|c|c|}
\hline \multirow{4}{*}{ Actual Symptoms } & \multicolumn{6}{|c|}{ The Studied Sample } & \multirow{2}{*}{\multicolumn{2}{|c|}{$\begin{array}{c}\text { Paired } T \text {-test } \\
P \text {-Value } \\
\end{array}$}} & \multirow{4}{*}{$\chi^{2}$} & \multirow{4}{*}{$P$ value } \\
\hline & & & & & & & & & & \\
\hline & \multicolumn{2}{|c|}{ Pre } & \multicolumn{2}{|c|}{ Post } & \multicolumn{2}{|c|}{$\begin{array}{l}\text { Follow up one } \\
\text { month }\end{array}$} & \multirow{2}{*}{$\begin{array}{c}\text { Pre VS. } \\
\text { Post }\end{array}$} & \multirow{2}{*}{$\begin{array}{l}\text { Pre VS. } 3 \\
\text { months post }\end{array}$} & & \\
\hline & No. & $\%$ & No. & $\%$ & No. & $\%$ & & & & \\
\hline Drowsy & 50 & 71.4 & 6 & 8.6 & 26 & 37.1 & $\begin{array}{c}7.9698 \\
0.000 \\
\end{array}$ & $\begin{array}{l}3.174 \\
0.003 \\
\end{array}$ & 29.120 & 0.000 \\
\hline Vomiting & 16 & 22.9 & 6 & 8.6 & 28 & 40 & $\begin{array}{l}1.537 \\
0.134 \\
\end{array}$ & $\begin{array}{l}1.642 \\
0.110 \\
\end{array}$ & 10.111 & 0.006 \\
\hline Mouth inflammation & 44 & 62.9 & 12 & 17.1 & 36 & 51.4 & $\begin{array}{l}1.160 \\
0.254 \\
\end{array}$ & $\begin{array}{l}1.160 \\
0.254 \\
\end{array}$ & 20.800 & 0.000 \\
\hline Tastes disturbance & 42 & 60 & 22 & 31.4 & 40 & 57.1 & $\begin{array}{l}0.274 \\
0.786\end{array}$ & $\begin{array}{l}0.274 \\
0.786\end{array}$ & 10.111 & 0.006 \\
\hline Mouth dryness & 24 & 34.3 & 6 & 8.6 & 26 & 37.1 & $\begin{array}{l}2.491 \\
0.018 \\
\end{array}$ & $\begin{array}{l}0.239 \\
0.812 \\
\end{array}$ & 8.667 & 0.013 \\
\hline Hair loss & 70 & 100 & 70 & 100 & 56 & 80 & $\begin{array}{l}3.688 \\
0.001 \\
\end{array}$ & $\begin{array}{l}2.915 \\
0.006 \\
\end{array}$ & 13.167 & 0.001 \\
\hline Diarrhea & 10 & 14.3 & 6 & 8.6 & 20 & 28.6 & $\begin{array}{l}0.702 \\
0.487 \\
\end{array}$ & $\begin{array}{l}1.406 \\
0.169 \\
\end{array}$ & 5.571 & 0.062 \\
\hline Constipation & 10 & 14.3 & 8 & 11.4 & 24 & 34.3 & $\begin{array}{l}0.329 \\
0.744 \\
\end{array}$ & $\begin{array}{l}2.227 \\
0.033 \\
\end{array}$ & 8.143 & 0.017 \\
\hline Tiredness & 60 & 85.7 & 6 & 8.6 & 26 & 37.1 & $\begin{array}{c}10.712 \\
0.000 \\
\end{array}$ & $\begin{array}{l}5.112 \\
0.000 \\
\end{array}$ & 39.929 & 0.000 \\
\hline Vain inflammation & 24 & 34.3 & 16 & 22.9 & 40 & 57.1 & $\begin{array}{l}1.435 \\
0.160 \\
\end{array}$ & $\begin{array}{l}2.260 \\
0.003 \\
\end{array}$ & 13.176 & 0.001 \\
\hline Vein pain & 30 & 42.9 & 6 & 8.6 & 22 & 31.4 & $\begin{array}{l}1.785 \\
0.083 \\
\end{array}$ & $\begin{array}{l}3.174 \\
0.008 \\
\end{array}$ & 17.636 & 0.000 \\
\hline Fever & 6 & 8.6 & 0 & 0 & 32 & 45.7 & $\begin{array}{l}4.212 \\
0.000 \\
\end{array}$ & $\begin{array}{l}0.255 \\
0.263 \\
\end{array}$ & 15.700 & 0.000 \\
\hline Depression & 26 & 37.1 & 12 & 17.1 & 14 & 20 & $\begin{array}{l}2.026 \\
0.051 \\
\end{array}$ & $\begin{array}{l}1.642 \\
0.040 \\
\end{array}$ & 6.143 & 0.046 \\
\hline Worry & 62 & 88.6 & 34 & 48.6 & 48 & 68.6 & $\begin{array}{l}4.761 \\
0.000 \\
\end{array}$ & $\begin{array}{l}2.026 \\
0.051 \\
\end{array}$ & 17.294 & 0.000 \\
\hline
\end{tabular}

*Significant $(P<0.05)$

Table 5: Distribution of Psychological Assessment among the Studied Patients Pre, Immediate and Follow Up Post Implementation of Tai Chi Exercise $(n=70)$

\begin{tabular}{|c|c|c|c|c|c|c|c|c|}
\hline \multirow{3}{*}{$\begin{array}{c}\text { Level of Total Anxiety and } \\
\text { Depression Scale }\end{array}$} & \multicolumn{6}{|c|}{ The Studied Sample $($ no. $=70)$} & \multirow{3}{*}{$F$-Value } & \multirow{3}{*}{$P$-Value } \\
\hline & \multicolumn{2}{|c|}{ Pre } & \multicolumn{2}{|c|}{ Immediate post } & \multicolumn{2}{|c|}{$\begin{array}{l}\text { Follow - up } \\
\text { One month }\end{array}$} & & \\
\hline & No. & $\%$ & No. & $\%$ & No. & $\%$ & & \\
\hline - Normal (0-7) & - & - & 36 & 51.4 & 24 & 34.3 & \multirow{3}{*}{627.869} & \multirow{3}{*}{0.000} \\
\hline - Borderline case (8-10) & - & - & 22 & 31.4 & 14 & 20 & & \\
\hline - Case (11-21) & 70 & 100 & 12 & 17.1 & 32 & 45.7 & & \\
\hline $\begin{array}{l}\text { Range } \\
\text { Mean } \pm \text { SD }\end{array}$ & 46.657 & 2504 & 16. & 8.78232 & 26.2 & .89562 & & \\
\hline \multirow{2}{*}{$T$-test } & \multicolumn{4}{|c|}{$\begin{array}{l}\text { Pre VS. Immediate post } \\
\end{array}$} & \multicolumn{4}{|c|}{ Pre VS. Follow-up } \\
\hline & \multicolumn{4}{|c|}{15.499} & \multicolumn{4}{|c|}{5.309} \\
\hline$P$-Value & \multicolumn{4}{|c|}{0.000} & \multicolumn{4}{|c|}{0.000} \\
\hline
\end{tabular}




\section{DISCUSSION}

As complementary and alternative therapy, TCC has become a popular fitness exercise worldwide. What kind of person is TCC suitable for? TCC can be practiced by anyone who wishes to improve physical and mental functions. Specifically, it has been shown to benefit patients with breast cancer, chronic heart failure, rheumatoid arthritis, and stroke (Ma et al., 2018).

Breast cancer is the most common cancer in women. Treatment for breast cancer can be disfiguring, expensive and painful and can significantly affect the quality of life, leading to various side effects such as depression and anxiety, fatigue, sleep disorders, and cognitive impairment (Ni et al., 2019).

Being diagnosed with breast cancer means dealing with many stressors, including side effects of treatment, fear of cancer recurrence, fear of death, impaired body image, and financial burden (Yamani Ardakani et al., 2020).

The present studied patients illustrated that around half studied patients were in the age group of more than 55 years with mean age $53 \pm 9$ years, married and majority of them living with their family and had not enough income. This result disagreed with (William et al. 2018) who mentioned in his study, that two thirds of all newly diagnosed female breast cancer patients are in the age 55 years older and this can be attributed to the postmenopausal period of life. According to Wang et al., (2016) in their study "Marital Status and Survival in Patients with Cancer", single patients were at significantly higher risk of presentation with metastatic cancer, under treatment, and death resulting from their cancer.

In relation to education level, majority of the sample had completed their University education. This study supported by the results Jiang et al., (2015) who reported that education plays a significant role in practicing Tai Chi in this study. Compared with people with a college education, people who have less than a high school education were less than three quarters had less likely to use Tai Chi, but majority of people with graduate degrees were more likely to practice. Higher education may enhance many aspects of people's decision making from gathering health information to attempting new ways for health improvement. Future research may investigate associations between education level and people's likelihood to try new things for health maintenance.

The study showed that the large percentage of studied samples' had Breast cancer on both site. While more than half had arthritis associated with disease. Related to weight one quarter of the studied patients were overweight around $90 \mathrm{~kg}$ and more with height 160: $175 \mathrm{~cm}$.

According to Karatas et al., (2017) who mentioned that the pattern of body-fat distribution also influences the risk of breast cancer. van den Berg et al., (2017) reported that; historically, weight loss in cancer patients has been the concern because of the association with poor prognosis. Breast cancer patients were unique in that they were more likely to gain weight following treatment than lose weight. Jung et al., (2020) documented that, there is an adverse relationship between weight change and prognosis for breast cancer patients and consequently patients likely to gain weight and are in need for nutritional advice on how to avoid gaining weight. This highlights a shift in the relationship between cancer and weight.

This study shows that there was highly statistically improvement in studied samples' actual symptoms pre, immediate and follow up test post program regarding Drowsy, Tiredness, Depression. And Worry, post implementation of Tai Chi Exercise program when comparing with pre, post of educational program, at ( $\left.p \leq 0.001^{* *}\right)$. This agree with Geib et al., (2014) who stated that although Tai Chi masters emphasize achieving peace through the body, mind, and respiratory adjustment, the precise physiological mechanisms of how Tai Chi works are still unclear. Many researchers have tried to study this. Geib and colleague have found changes in cytokine production following Tai Chi practice to reduce pain in some healthy Volunteers.

This study confirmed that there was high statistically significant differences between pre and post in Level of total anxiety and depression scale also were high significant differences between pre and follow up at ( $p \leq$ $\left.0.001^{* *}\right)$ and $\left(p \leq 0.05^{*}\right)$. In accordance with Janelsins et al., (2011) have observed reduced cellular inflammatory responses and reduced expression of genes encoding proinflammatory mediators among breast cancer survivors, Hence, the physiological mechanisms of Tai Chi may be person and health status specific. This mindbody approach may be considered a therapeutic option in the multidisciplinary management of fibromyalgia (Kreutz et al., 2019).

Generally, the present study revealed that the intervention of Tai Chi excersis had a positive effect on breast cancer patients physical and psychological status. This match with Wang et al., (2018) who suggest that TCC may be an efficacious intervention for enhancing 
functional capacity among breast cancer survivors and may support the need for larger randomized, controlled clinical trials to further elucidate these relationships.

Conversely, these data suggested that this form of exercise did not cause rapid and excessive weight loss either, which is often an early clinical indication of poorer responses to cancer treatment (Palesh et al., 2018).

\section{CONCLUSION}

The participants of the study felt that tai chi had been greatly beneficial to them, both in terms of improving physiological well-being but also as vital in improving their relationship with their cancer. Tai chi effect on side effects of their treatments, such as lymphedema, nausea and vomiting. Improvements in study sample physical status in addition, reduce level of fatigue, anxiety and depression.

\section{Recommendations}

The study is recommended that adequate and variable scientific books or pamphlets should be available in areas of breast cancer treatment, with simple explanations including materials related to Tai Chi Exercise and practices.

\section{Conflict of Interests}

The authors declare that they have no conflict of interest

\section{ACKNOWLEDGMENT}

Special thanks and gratitude are offered to the medical staff and patients in oncology department at Al Fardose Clinic in health insurance, Mansoura, Egypt., Egypt for their cooperation and support during conducting this study.

\section{REFERENCES}

Berhili, S., Kadiri, S., Bouziane, A., Aissa, A., Marnouche, E., Ogandaga, E., Echchikhi, Y., Touil, A., Loughlimi, H., Lahdiri, I., El Majjaoui, S., El Kacemi, H., Kebdani, T. \& Benjaafar, N., (2017). Associated factors with psychological distress in Moroccan breast cancer patients: A cross-sectional study. The Breast, 31, pp 26-33.

Bjelland, I. (2002). The validity of the Hospital Anxiety and Depression Scale. An updated literature review. Journal of Psychosomatic Research. 52(2), pp 69-77.

Ding, K., Zhang, X., Zhao, J., Zuo, H., Bi, Z. \& Cheng, H. (2020). Managing Cancer and Living Meaningfully (CALM) Intervention on Chemotherapy-Related Cognitive Impairment in Breast Cancer Survivors. Integrative Cancer Therapies, 19, pp 1-10.

Fabi, A., Bhargava, R., Fatigoni, S., Guglielmo, M., Horneber, M., Roila, F. \& Ripamonti, C. I. (2020). Cancer-related fatigue: ESMO Clinical Practice Guidelines for diagnosis and treatment. Annals of Oncology, 31(6), pp 713-723.

Gany, F., Ayash, C., Raad, N., Wu, M., Roberts-Eversley, N., Mahmoud, H., \& El-Shinawi, M. (2020). Financial and food security challenges of Egyptian women undergoing breast cancer treatment. Supportive Care in Cancer, 28(12), pp 5787-5794.

Geib, R. W., Li, H. \& Waite, G. N. (2014). A pilot study on the effect of tai chi exercise on peripheral blood cytokines associated with nociceptive pain in healthy volunteers. Biomedical Sciences Instrumentation, 50, pp 125-131.

Gilchrist, S., Barac, A., Ades, Ph., Alfano, C., Franklin, B., Jones,L., Gerche , A., Ligibel, J., Lopez, G., Madan, K., Oeffinger, K., Salamone, J., Scott, J., Squires, R., Thomas, R., Jacobson, V., Wright, J. \& On behalf of the American Heart Association Exercise, (2019). Cardiac Rehabilitation, and Secondary Prevention Committee of the Council on Clinical Cardiology; Council on Cardiovascular and Stroke Nursing; and Council on Peripheral Vascular Disease 139, pp 997-1012.

Hissa, J., Connolly, A., Timulak, L. \& Hession, N. (2020). Emotion-focused perspective on breast cancer patients' experiences of comorbid anxiety and depression: a qualitative case analysis of three clients' in-session presentations. Person-Centered \& Experiential Psychotherapies, 19(2), pp 134-153.

Janelsins, M.C., Davis, P.G., Wideman, L., Katula, J.A., Sprod, L.K., Peppone, L.J., Palesh, O.G., Heckler, C.E., Williams, J.P., Morrow, G.R. \& Mustian, K.M. (2011). Effects of Tai Chi Chuan on insulin and cytokine levels in a randomized controlled pilot study on breast cancer survivors. Clinical breast cancer, 11(3), pp 161-170.

Jiang, D., Kong, W. \& Jiang, J.J. (2015). Study of tai chi practice in the United States. Annals of Community Medicine and 
Practice, 1,p.1005.

Jung, Y., Hüsing, A., Behrens, S., Krzykalla, J., Obi, N., Becher, H. \& Chang Claude, J. (2020). Post diagnosis weight change is associated with poorer survival in breast cancer survivors: A prospective population based patient cohort study. International Journal of Cancer, 148(1), pp 18-27

Karatas, F., Erdem. U., Sahin, S., Aytekin, A., Yuce, D., Sever, R. \& Altundag, K. (2017). Obesity is an independent prognostic factor of decreased pathological complete response to neoadjuvant chemotherapy in breast cancer patients. The Breast, 32, pp 237-244.

Kreutz, C., Schmidt, M. E., \& Steindorf, K. (2019). Effects of physical and mind-body exercise on sleep problems during and after breast cancer treatment: a systematic review and meta-analysis. Breast Cancer Research and Treatment, 176, pp 1-15.

Liu, L., Petrich, S., McLaren, B., Kelly, L. \& Baxter, G. D. (2018). An integrative Tai Chi program for patients with breast cancer undergoing cancer therapy: study protocol for a randomized controlled feasibility study. Journal of Integrative Medicine, 16(2), pp 99-105.

Ma, C., Zhou, W., Tang, Q. \& Huang, S. (2018). The impact of group-based Tai chi on health-status outcomes among community-dwelling older adults with hypertension. Heart \& Lung, 47(4), pp 337-344.

Nomura, T., Nagano, K., Takato, J., Ueki, S., Matsuzaki, Y. \& Yasumura, S. (2011). The development of a Tai Chi exercise regimen for the prevention of conditions requiring long-term care in Japan. Archives of Gerontology and Geriatrics, 52(3), pp e198-e203.

Ni, X., Chan, R. J., Yates, P., Hu, W., Huang, X. \& Lou, Y. (2019). The effects of Tai Chi on quality of life of cancer survivors: a systematic review and meta-analysis. Supportive Care in Cancer, 27, pp 3701-3716.

Osborn, J., Ajakaiye, A., Cooksley, T. \& Subbe, C. P. (2020). Do mHealth applications improve clinical outcomes of patients with cancer? A critical appraisal of the peer-reviewed literature. Supportive Care in Cancer, 28(3), pp 14691479.

Palesh, O., Scheiber, C., Kesler, S., Mustian, K., Koopman, C. \& Schapira, L. (2018). Management of side effects during and post treatment in breast cancer survivors. The Breast Journal, 24(2), pp 167-175.

Pan, Y., Yang, Y., Dong, Y., Li, N., Liang, H. \& Cui, Q. (2018). Heterogeneity Factor Analysis of Studies Evaluating the Effect of Tai Chi on Improving the Overall Quality of Life in Patients with Breast Cancer. Clinical Medicine Research, 7(3), pp 57.

Park, E., Gelber, S., Rosenberg, S., Seah, D., Schapira, L., Come, S. \& Partridge, A., (2018). Anxiety and depression in young women with metastatic breast cancer: a cross-sectional study. Psychosomatics, 59(3), pp 251-258.

Van den Berg, A., Winkels, M., de Kruif, C., van Laarhoven, M., Visser, M., de Vries, M. \& Kampman, E. (2017). Weight change during chemotherapy in breast cancer patients: a meta-analysis. BMC Cancer, 17(1), pp 259.

Wang, C., Schmid, C. H., Fielding, R. A., Harvey, W. F., Reid, K. F., Price, L. L. \& McAlindon, T. (2018). Effect of tai chi versus aerobic exercise for fibromyalgia: comparative effectiveness randomized controlled trial. BMJ, 21(3) pp 360 .

Wang, D., Qian, J., Bai, S., Li, N., Jiang, Q. \& Yao, J. (2016). Marital status independently predicts pancreatic cancer survival in patients treated with surgical resection: an analysis of the SEER database. Oncotarget, 7(17): pp 24880-24887.

William, F., Mekkawy, M., Azer, Z., Saleh, A. \& Khallaf, M. (2018). Knowledge, Attitude, and Practices Regarding Nutrition for Patients With Chemotherapy. Assiut Scientific Nursing Journal, 6(15), pp119-125.

Yamani Ardakani, B., Tirgari, B. \& Roudi Rashtabadi, O. (2020). Body image and its relationship with coping strategies: The views of Iranian breast cancer women following surgery. European Journal of Cancer Care, 29(1), pp 13191.

Zigmund, A. (1983). The hospital anxiety and depression scale. Acta Psychiatrica Scandinavica, 67, pp 361-370 